\title{
Determinan Kesehatan dalam Perspektif Islam: Studi Pendahuluan
}

\author{
Eka Nurhayati, Susan Fitriyana \\ Departemen Ilmu Kesehatan Masyarakat, Fakultas Kedokteran, Universitas Islam Bandung
}

\begin{abstract}
Abstrak
Ajaran Islam meyakini bahwa kesehatan merupakan hak asasi manusia dan anugerah kedua terbesar dari Allah setelah keimanan. Dalam upaya menjaga kesehatan, dibutuhkan keseimbangan antara berbagai determinan kesehatan yang merupakan perpaduan faktor-faktor yang dapat memengaruhi kesehatan baik individu maupun masyarakat. Penelitian ini bertujuan mengidentifikasi dan mendeskripsikan determinan kesehatan dalam perspektif Islam. Penelitian ini merupakan penelitian kualitatif etnografis yang dilakukan di Kota Bandung. Pengambilan data dilakukan pada bulan April-Oktober 2019. Penelitian dilakukan dengan wawancara mendalam kepada 6 orang ulama yang memiliki pendidikan minimal strata dua dalam bidang agama Islam. Analisis data dilakukan dengan cara reduksi, transkripsi, koding, dan tema. Validitas data dilakukan dengan cara triangulasi. Hasil penelitian menunjukkan bahwa determinan kesehatan dalam perspektif Islam terdiri atas: (i) iman dan ibadah (ii) perilaku, (iii) lingkungan, (iv) sosial, (v) genetik, dan (vi) pelayanan kesehatan. Simpulan penelitian adalah determinan kesehatan dalam Islam yang paling utama adalah keimanan dan ibadah, ditunjang pula oleh determinan lainnya, yaitu perilaku, lingkungan, sosial, genetika, dan pelayanan kesehatan. Keseimbangan seluruh determinan kesehatan akan menciptakan kesehatan spiritual yang akan memengaruhi pencapaian kesehatan jiwa, fisik dan sosial.
\end{abstract}

Kata kunci: Determinan, islam, kesehatan, perspektif

\section{Determinants of Health in Islamic Perspective: a Pilot Study}

\begin{abstract}
Islamic teachings believe that health is a human right and the second main gift from God after the faith. In an effort to preserve health, a balance is needed between determinants of health which is a combination of factors that can affect the health of both individuals and society. This study aims to identify and describe health determinants in an Islamic perspective. This research is an ethnographic qualitative study conducted in Bandung. Data collection was held in April-October 2019. The study was conducted with in-depth interviews to 6 Islamic religion leader who have a minimum of master education in Islamic religion. Data analysis was done by reduction, transcription, coding and themes. Data validity was done by triangulation. The results showed that health determinants in Islamic perspective consisted of: (i) faith and worship (ii) health behavior, (iii) environment, (iv) social, (v) genetic, and (vi) health services. The conclusion from the research showed that the most important determinants of health in Islam is faith and worship, also supported by other determinants such as behavior, environment, social, genetics and health services. The balance of all health determinants will create spiritual health that will support the achievement of mental, physical and social health.
\end{abstract}

Keywords: Determinants, health, islam, perspective

Korespondensi: Eka Nurhayati, dr., MKM. Departemen Ilmu Kesehatan Masyarakat, Fakultas Kedokteran Universitas Islam Bandung Jl. Tamansari No. 22, Kota Bandung, Provinsi Jawa Barat Telepon: (022) 4203368 Faksimile: - HP: 081320623569 E-mail: nurhayatieka25@gmail.com 


\section{Pendahuluaxsn}

Ajaran Islam mengatur seluruh sendi kehidupan umat muslim baik kehidupan sebagai individu, keluarga maupun bermasyarakat termasuk dalam aspek kesehatan. ${ }^{1,2}$ Ajaran Islam meyakini bahwa kesehatan merupakan hak asasi manusia dan anugerah kedua terbesar dari Allah setelah keimanan. ${ }^{1}$ Kesehatan merupakan modal utama bagi umat muslim untuk menjalankan kehidupan dan kewajibannya beribadah di dunia. Berdasar atas pandangan tersebut, umat muslim diberikan tanggung jawab untuk menjaga kesehatan dan mengupayakan pengobatan jika sakit..,3

Dalam upaya menjaga kesehatan, dibutuhkan keseimbangan dari berbagai determinan kesehatan. Determinan kesehatan menurut World Health Organization (WHO) merupakan perpaduan faktorfaktor yang dapat memengaruhi kesehatan baik individu maupun masyarakat. ${ }^{4}$ Teori klasik mengenai determinan kesehatan dicetuskan oleh H. L. Blum pada tahun 1981 melalui bukunya yang berjudul Planning of Health. Teori ini menyatakan bahwa kesehatan juga dipengaruhi oleh 4 determinan, yaitu lingkungan, perilaku, pelayanan kesehatan, dan genetik. Faktor lingkungan merupakan faktor yang paling memengaruhi status kesehatan, yaitu sebesar $45 \%$, disusul oleh faktor perilaku sebesar $30 \%$, faktor pelayanan kesehatan $20 \%$, dan faktor genetik $5 \% .{ }^{5}$

Ajaran Islam diketahui mempunyai keterkaitan dengan upaya promosi kesehatan baikindividu maupun masyarakat, termasuk juga upaya untuk menjaga keseimbangan determinan kesehatan. Sayangnya, saat ini Islam sering kali diidentikkan dengan kemiskinan dan perilaku hidup yang kurang sehat. Praktikpraktik pencegahan penyakit dan promosi kesehatan dianggap lebih banyak lahir dari ilmu kesehatan barat. ${ }^{6}$ Penelitian mengenai determinan kesehatan dalam perspektif islam penting dilakukan untuk dapat menciptakan model promosi kesehatan yang sesuai bagi umat muslim. Penelitian ini bertujuan untuk mengidentifikasi dan mendeskripsikan determinan kesehatan dalam perspektif Islam.

\section{Metode}

Penelitian ini merupakan penelitian pendahuluan yang dilakukan untuk menciptakan model promosi kesehatan yang sesuai dengan ajaran Islam bagi umat muslim. Penelitian ini merupakan penelitian kualitatif etnografis. ${ }^{7}$ Subjeknya adalah ulama atau ahli yang memperdalam ilmu agama Islam secara akademik sampai dengan strata dua sejumlah 6 orang. Pengambilan sampel pada penelitian ini dilakukan dengan metode non probability sampling dengan cara snowball sampling ${ }^{7,8}$ serta ulama yang menjadi subjek merupakan rekomendasi dari subjek sebelumnya. Penelitian dilakukan di Kota Bandung sejak bulan April sampai dengan Oktober 2019. Pengambilan data dilakukan pada bulan Juni sampai dengan Juli 2019.

Proses pengolahan data dilakukan dengan cara mengolah hasil wawancara mendalam menjadi bentuk tertulis melalui proses transkripsi. ${ }^{8}$ Langkah selanjutnya adalah dengan melakukan reduksi, yaitu mengurangi bagian-bagian yang kurang bermakna dari proses wawancara tanpa mengubah maknanya. Proses selanjutnya adalah coding, yaitu memberikan kode-kode tertentu terhadap hasil transkripsi menggunakan software Nvivo 12 plus for Mac. Kodekode tersebut kemudian dikumpulkan dan dianalisis menjadi tema-tema yang sesuai dengan variabel penelitian, yaitu determinan kesehatan. Validitas data dilakukan dengan cara triangulasi metodologis karena data yang telah dikumpulkan kemudian dibandingkan dan dikontraskan.8,9

\section{Hasil}

Hasil penelitian menunjukkan bahwa dalam Islam, manusia merupakan komponen yang holistik terdiri atas raga, jiwa, sosial, dan spiritual. Berdasar atas hal tersebut maka keadaan sehat yang harus dicapai bukan saja sehat fisik, melainkan sehat secara holistik pula. Hasil penelitian menunjukkan bahwa tema yang muncul tentang determinan kesehatan dalam perspektif Islam terdiri atas: (i) iman dan ibadah, (ii) perilaku, (iii) lingkungan, (iv) sosial, (v) genetik, dan (vi) pelayanan kesehatan.

\section{Iman dan ibadah}

Determinan kesehatan paling utama dalam perspektif Islam berdasar atas penelitian adalah iman dan ibadah. Seluruh narasumber menyatakan bahwa kesehatan yang paling utama adalah kesehatan spiritual yang hanya dapat dicapai dengan keimanan dan penegakan ibadah. Hal ini sesuai dengan rukun iman dan rukun islam dalam ajaran Islam.

Kesehatan spiritual yang baik dikatakan dapat membawa berpengaruh positif pada kesehatan raga, jiwa, dan sosial seorang muslim. Hal ini dinyatakan dalam hadits Bukhari dan Muslim yang dikutip oleh narasumber:

"Dan beliau mengisyaratkan, bahwa beliau menggambarkan ada semacam gumpalan daging. Kalau gumpalan daging ini sehat, badanmu sehat, tapi kalau gumpalan ini sakit, maka akan jadi sakit. Disebut hati itu, Qalbun. Dalam beberapa ayat, qalbun itu diartikan akal." (Narasumber 6)

Para narasumber juga menyatakan terdapat keterkaitan secara langsung maupun tidak langsung antara ibadah yang dilakukan dan kesehatan raga, jiwa maupun sosial dan hal tersebut telah dibuktikan secara ilmiah. Beberapa contoh ibadah antara lain sholat, puasa, thawaf, dan sai disebutkan narasumber berpengaruh langsung pada kesehatan raga dan jiwa. Zakat disebutkan dapat melepaskan hormonhormon yang membuat jiwa menjadi lebih bahagia, serta membaca dan mendengarkan Quran dapat meningkatkan keimanan sehingga berdampak pada kesehatan jiwa. Al-Quran bagi kaum muslimin selain sebagai pedoman hidup dipercaya juga sebagai syifa atau penyembuh. 


\section{Perilaku}

Seluruh narasumber menekankan bahwa Islam telah sejak dulu mengajarkan umat muslim untuk menjaga kesehatan pribadi, keluarga, maupun masyarakat melalui perilaku hidup yang baik dan bersih. Islam tidak hanya mengajarkan perilaku hidup yang berhubungan dengan ibadah seperti thaharah atau bersuci, namun juga mengatur perilaku yang sering kali dianggap remeh seperti cara makan dan minum, konsumsi makanan yang halal dan thoyib, cara mandi, aktivitas seksual, dan lain sebagainya.

Narasumber juga menyatakan bahwa agama Islam mengajarkan untuk selalu menjaga kesehatan melalui aktivitas fisik. Dalam Al-Quran, Allah menyatakan bahwa Ia menciptakan malam dan siang secara bergantian. Siang dipergunakan untuk beraktivitas atau bekerja, sementara malam digunakan untuk beristirahat. Seorang narasumber menyatakan:

"Dan kami menciptakan siang untuk bekerja, dan kami menciptakan malam untuk beristirahat. Kalau malam ini harus istirahat. Kalau siang harus untuk bekerja. Dihubungkan dengan manusia sebagai Al Bassar. Al Bassar itu manusia akan berinteraksi dengan sekelilingnya. Ada matahari, sistem udara. Kalau pada malam hari udara itu kan semakin sedikit karena diambil oleh pohon-pohon juga dan matahari itu sudah tidak ada, sehingga darah itu mulai mengental, sehingga saat darah mengental, maka aktivitasnya harus istirahat. Itu yang paling terbaik. Kalau digunakan, maka akan jadi problem. Allah menyuruhnya bekerja siang hari. Kenapa siang hari? Oksigennya optimal, darahnya cair, ada sistem matahari dan udara itu optimal. Orang bisa bekerja pada siang hari dia tidak akan sakit."(Narasumber 3)

\section{Lingkungan}

Keadaan lingkungan yang terjaga kebersihannya disebutkan oleh narasumber sebagai faktor penting dalam hal mewujudkan keadaan sehat. Lingkungan yang baik selain menunjang kesehatan fisik, akan menunjang ibadah yang lebih baik sehingga akan meningkatkan keimanan dan kesehatan spiritual.

Seorang muslim disebutkan memiliki tanggung jawab bukan hanya pada dirinya, keluarga dan masyarakat melainkan juga memiliki tanggung jawab kepada seluruh mahluk dalam alam semesta sehingga ia wajib menjaga keseimbangan lingkungan. Hal tersebut yang saat ini jarang disadari oleh seorang muslim sehingga ia dapat melakukan pencemaran lingkungan tanpa merasa telah berdosa. Seorang narasumber menyatakan:

"Al Quran dilempar-lempar, itu merasa berdosa. Tapi kalau mencemari alam, menggunduli gunung, mencemari sungai, itu tidak merasa berdosa. Padahal sama berdosanya." (Narasumber 3)

\section{Sosial}

Hubungan antarsesama manusia dinyatakan oleh narasumber sebagai salah satu faktor yang dapat memengaruhi kesehatan seorang muslim. Salah seorang narasumber menyebutkan bahwa dalam Al-Quran, manusia memiliki banyak sebutan, salah satunya adalah Annas yang mengacu pada manusia sebagai bagian dari tatanan sosial kemasyarakatan. Narasumber lainnya menyebutkan bahwa Rasulullah mengajarkan agar seorang muslim memiliki ahlak yang baik kepada sesama manusia agar tidak memiliki banyak musuh. Terdapat penyakit-penyakit hati seperti iri, dengki, sombong, dendam, dan buruk sangka kepada orang lain dapat mengganggu kesehatan jiwa sehingga kemudian dapat memengaruhi kesehatan raga dan dapat menimbulkan keluhan psikosomatik.

\section{Genetik}

Salah satu narasumber menyatakan bahwa dalam Islam diketahui bahwa penyakit dapat disebabkan oleh maziyah atau keturunan. Narasumber lainnya menyatakan bahwa faktor genetik sangat berperan penting dalam kesehatan. Islam mengajarkan untuk memilih pasangan berdasar atas kriteria tertentu. Saudara kandung, saudara sepersusuan, dan terdapat hubungan darah dalam keluarga tidak diperbolehkan menikah karena dapat menimbulkan risiko munculnya gen resesif.

\section{Pelayanan Kesehatan}

Tema lain yang muncul dalam penelitian ini adalah pelayanan kesehatan. Narasumber menyatakan bahwa Islam memandang upaya pelayanan kesehatan dapat membantu mencegah penyakit dan memulihkan kondisi kesehatan. Ketika seorang muslim menderita sakit maka Islam mengajarkan untuk berdoa dan berikhtiar. Doa dilakukan dengan cara menggiatkan ibadah-ibadah dan memohon kesembuhan pada Allah, sedangkan ikhtiar dilakukan dengan pergi berobat seperti yang diperintahkan oleh Rasulullah.

Islam memandang kesembuhan sebagai hak prerogatif Allah. Dokter, tenaga kesehatan lainnya, serta obat-obatan merupakan perantara Allah dan bukan faktor penentu terjadinya kesembuhan. Salah seorang narasumber menyatakan bahwa Rasulullah pernah berpesan untuk berobat kepada tenaga yang ahli karena jika suatu urusan diserahkan kepada yang bukan ahlinya maka yang didapat adalah kehancuran.

\section{Pembahasan}

Hasil penelitian ini menunjukkan bahwa Islam memandang manusia sebagai satu kesatuan yang utuh antara raga, jiwa, dan spiritual. Hal ini sesuai dengan hasil penelitian Laluddin ${ }^{10}$ yang menyatakan bahwa Islam memandang manusia terdiri atas aspek eksternal, yaitu jasmani dan aspek internal yang terdiri atas ruh dan akal. Kedua aspek internal dan eksternal ini saling terkait dan memengaruhi satu sama lain. Kesehatan jasmani dibutuhkan agar manusia dapat melaksanakan ibadah dengan baik sehingga dapat mencapai kesehatan mental dan spiritual yang baik pula. ${ }^{10,11}$

Determinan kesehatan yang paling utama dalam 
perspektif Islam adalah keimanan dan pelaksanaan ibadah dengan tata cara yang benar dan dilakukan dengan konsisten guna meningkatkan kesehatan spiritual..$^{1,3,6}$

Kesehatan spiritual nanti akan berpengaruh positif terhadap kesehatan raga, jiwa, dan sosial. Hal ini menjelaskan bahwa dalam perspektif Islam, kesehatan spiritual merupakan dimensi kesehatan yang diutamakan. Kajian pustaka terhadap 1.200 artikel yang pernah dilakukan oleh Koenig ${ }^{12}$ membuktikan bahwa ibadah memiliki dampak positif terhadap kesehatan mental. Hal ini disebabkan karena ibadah yang dilakukan dapat memfasilitasi mekanisme coping sehingga dapat menurunkan tingkat depresi, stress kecemasan, dan meningkatkan emosi positif. Kesehatan mental kemudian akan dapat memengaruhi kesehatan fisik melalui jalur psikologis.

Pilar ibadah utama yang disebut sebagai rukun Islam merupakan tonggak ibadah yang sejatinya dapat mengisi kebutuhan spiritual, mental, dan juga fisik. ${ }^{1,10,13}$ Kewajiban utama, yaitu mengucapkan dua kalimat syahadat sebagai bukti ketauhidan senantiasa mengingatkan muslim untuk takut kepada Allah sehingga terhindar dari perbuatan dosa. Hal ini akan berdampak positif pada kesehatan sosial karena muslim dengan karakter tersebut dapat menjadi anggota masyarakat yang baik dan bermanfaat bagi masyarakat sekitarnya. ${ }^{10}$ Kewajiban lainnya seperti shalat dan puasa bukan saja bermanfaat bagi fisik, namun juga sebagai wahana meditasi intelektual, upaya perbaikan moral, dan persembahan spiritual kepada Sang Khalik.10,13 Zakat bermanfaat dalam upaya peningkatan kesehatan spiritual, jiwa, dan sosial karena melalui zakat manusia diajarkan untuk berbagi dengan sesama. ${ }^{10}$ Ibadah haji bermanfaat untuk pemurnian jiwa dan peningkatan kesehatan spiritual. ${ }^{13}$

Kesehatan spiritual ternyata juga terbukti dapat meningkatkan perilaku hidup yang sehat. Koenig ${ }^{12}$ membuktikan bahwa pembatasan dan aturan yang ditetapkan dalam suatu agama membantu untuk mengurangi perilaku buruk seperti konsumsi minuman keras, obat-obatan terlarang, serta rokok. ${ }^{12}$ Kesehatan spiritual juga membantu mempromosikan hidup sehat seperti aktivitas fisik, diet sehat, serta aktivitas seksual yang sehat., ${ }^{1,6}$ Studi pustaka yang dilakukan oleh Koenig ${ }^{12}$ menunjukkan bahwa perilaku hidup yang sehat berdampak pada kesehatan fisik dan memperpanjang usia.

Rahman dan Kareem $^{2}$ dalam artikelnya yang berjudul Islamic Guidelines for Healthful Living mengumpulkan berbagai aturan dalam Islam terkait perilaku hidup sehat. Rahman dan Kareem ${ }^{2}$ membuktikan bahwa Al-Quran dan hadits sebagai pedoman hidup umat muslim telah memuat aturan mulai dari aturan membersihkan diri melalui wudhu, menjaga higienitas oral dan gigi menggunakan siwak, perintah menyusui bayi hingga usia 2 tahun, diet sehat dengan mencontoh pola makan Rasul, pelarangan alkohol, perilaku sanitasi sehat dengan melarang melakukan buang air besar di tempat-tempat tertentu, serta sikap dan perilaku dalam menghadapi wabah penyakit di suatu daerah serta pola perilaku aktivitas seksual yang sehat.

Tema lainnya yang muncul dalam penelitian ini adalah lingkungan. Hasil penelitian ini sesuai dengan penelitian yang dilakukan oleh Ashtankar ${ }^{14}$ yang menyatakan bahwa Islam memandang lingkungan sebagai milik dan ciptaan Allah SWT yang diciptakan dalam keadaan seimbang baik kuantitas maupun kualitasnya. Keadaan ini menunjukkan bahwa untuk dapat mencapai kesehatan lingkungan yang optimal dibutuhkan keseimbangan ekosistem. Manusia yang diturunkan ke muka bumi memiliki tanggung jawab sebagai khalifah di muka bumi bertanggung jawab untuk menjaga keseimbangan tersebut. ${ }^{1,3,6,14}$

Lingkungan dalam pandangan Islam bukan hanya lingkungan alam, namun juga meliputi lingkungan sosial. Islam memandang masyarakat sebagai satu kesatuan utuh, seperti juga tubuh manusia. ${ }^{10}$ Keberadaan manusia akan memengaruhi manusia lainnya sehingga dalam islam manusia yang paling baik adalah manusia yang bermanfaat bagi sesamanya. ${ }^{1,10}$ Pilar ibadah agama islam, yaitu rukun islam merupakan sarana pembentukan karakter sehingga tercipta umat muslim yang memiliki ahlak yang baik terhadap sesama serta tercipta masyarakat yang harmoni. ${ }^{10}$

Determinan kesehatan lainnya yang didapatkan dalam penelitian ini adalah genetik. Ghareeb ${ }^{15}$ dalam artikelnya menunjukkan bahwa ilmu genetika telah tercantum dalam Al-Quran dan Al-Hadits sejak ribuan tahun yang lalu. Rasulullah Muhammad SAW menekankan umat muslim untuk memilih pasangan dengan cermat karena kelainan genetika tidak hanya menimbulkan cacat fisik, namun juga dalam bentuk gangguan karakter dan penyakit. ${ }^{15}$

Determinan kesehatan terakhir yang muncul dalam penelitian ini adalah pelayanan kesehatan. Islam meyakini kesehatan sebagai suatu rahmat sekaligus ujian yang harus dijaga oleh manusia. Islam bahkan menekankan bahwa promosi dan prevensi kesehatan adalah hal yang lebih utama. ${ }^{3,6}$

Keadaan ini menyiratkan bahwa tugas pelayanan kesehatan yang lebih utama adalah tugas untuk mempertahankan keadaan sehat dan mencegah kejadian penyakit.

Jika manusia terkena penyakit, ajaran Islam pun meyakini bahwa Allah telah menyediakan obatnya. Ajaran Islam meyakini bahwa kesembuhan merupakan hak mutlak Allah SWT. Rahman ${ }^{3}$ dalam artikelnya menyatakan bahwa umat muslim harus memegang teguh rukun iman sehingga wajib meyakini bahwa penyakit merupakan ketentuan dari Allah SWT dan hanya dapat disembuhkan oleh Allah SWT. Ketika penyakit menyerang, tugas utama manusia adalah memohon kesembuhan kepada Allah SWT melalui peningkatan kualitas ibadah. Kewajiban lainnya adalah mencari pengobatan yang sesuai dengan ajaran Islam, baik itu pengobatan modern ataupun pengobatan komplementer dan alternatif. ${ }^{3}$

\section{Simpulan}

Simpulan dari penelitian adalah bahwa determinan kesehatan dalam Islam yang paling utama adalah keimanan dan ibadah, ditunjang pula oleh determinan lainnya, yaitu perilaku, lingkungan, sosial, genetika, 
dan pelayanan kesehatan. Keseimbangan seluruh determinan kesehatan akan menciptakan kesehatan spiritual yang akan menunjang pencapaian kesehatan jiwa, fisik, dan sosial.

\section{Ucapan Terima Kasih}

Kami menghaturkan rasa terima kasih kepada bagian Ilmu Kesehatan Masyarakat Fakultas Kedokteran Universitas Islam Bandung serta Lembaga Studi Islam dan Pengembangan Kepribadian (LSIPK) Universitas Islam Bandung atas segala bantuan yang diberikan pada penelitian ini.

\section{Daftar Pustaka}

1. Al Khayat MH. Health as human right in islam. Cairo: World Health Organization; 2004.

2. Rahman MT, Kareem JBA. Islamic guidelines for healthful living. JIMA [Internet]. 2007 (diunduh 26 Maret 2019);39:158-67. Tersedia dari: https://www.encyclopedia.com/science/ encyclopedias-almanacs-transcripts-and-maps/ islamic-perspectives

3. Rahman MT. Health and healing in islam: links and gaps with (post) modern practices. Bangladesh J Med Sci. 2015;14(02):119-29.

4. World Health Organization. Health impact assessment (HIA).[Internet]. [diunduh 5 April 2019]. Tersedia dari: https://www.who.int/hia/ en/

5. Blum HL. Planning for health. New York: Human Sciences Press; 1981.
6. Ar A, Aidalina M. A review of the islamic approach in public health practices. Int $\mathrm{J}$ Public Heal Clin Sci. 2014;1(2):1-13.

7. Mohajan H. Qualitaive research methodology in social sciences and related subjects. J Econ Dev Environ People. 2018;7(1):1-29.

8. Lopez V, Whitehead D. Sampling and data collection in qualitative research. Nurs Midwifery Res Methods Apprais evidence-based Pract. 2013 Jan:123-40.

9. Huberman AM, Miles MB. Manajemen data dan metode analisis. Dalam: Denzin NK, Lincoln YS, pengarang. The handbook of qualitative research. Yogyakarta: Pustaka Pelajar; 2009. hlm. 591-609.

10. Laluddin H. Conception of society and its characteristics from an islamic perspective. Int $\mathrm{J}$ Islam Thought. 2014;6(1):12-25.

11. Yousofi H. Human health and religious practices in quraan. Procedia - Soc Behav Sci. 2011;30:248790.

12. Koenig HG. Religion, spirituality, and health: the research and clinical implications. Int Sch Res Netw. 2012:1-33.

13. Zaw CC, Myat M, Mohd O. Five pillars of islam in relation with physical and spiritual health. 2nd World Congr Integr Islam Focus Med Heal Care Sci (2WCII 2016), 21st-23rd Oct 2016, Kuantan, Pahang Darul Makmur. 2016;16(1):53049.

14. Ashtankar OM. Islamic perspectives on environmental protection. Int $J$ Appl Res. 2016;2(1):438-41.

15. Ghareeb BAA. Human genetics and islam: scientific and medical aspects. JIMA. 2011;43:8390. 